\title{
In vivo coupling of dendritic complexity with presynaptic density in primary tauopathies
}

Elijah Mak $(\mathrm{PhD})^{\mathrm{a}^{*}}$, Negin Holland $(\mathrm{MRCP})^{\mathrm{b}, \mathrm{d}^{*}}$, P. Simon Jones, $(\mathrm{MSc})^{\mathrm{b}}$, George Savulich $(\mathrm{PhD})^{\mathrm{a}}$, Audrey Low $(\mathrm{MSc})^{\mathrm{a}}$, Maura Malpetti $(\mathrm{MSc})^{\mathrm{b}}$, Sanne $\mathrm{S}$ Kaalund $(\mathrm{PhD})^{\mathrm{b}}$, Luca Passamonti (MRCP, PhD) $)^{\mathrm{b}}$, Timothy Rittman (MRCP, PhD) ${ }^{\mathrm{b}}$, Rafael Romero-Garcia $(\mathrm{PhD})^{\mathrm{a}}$, Roido Manavaki $(\mathrm{PhD})^{\mathrm{c}}$, Guy B. Williams $(\mathrm{PhD})^{\mathrm{c}}$, Young T. Hong $(\mathrm{PhD})^{\mathrm{c}}$, Tim D. Fryer $(\mathrm{PhD})^{\mathrm{b}, \mathrm{c}}$, Franklin I. Aigbirhio (DPhil) ${ }^{\mathrm{b}}$, John T O’Brien (FRCPsych, DM) ${ }^{\mathrm{a}, \mathrm{d} * \star}$, James B Rowe $(\mathrm{FRCP}, \mathrm{PhD})^{\mathrm{b}, \mathrm{d}, \mathrm{e} * *}$

* Joint first authors, ${ }^{* \star}$ Joint senior authors

\section{AFFILIATIONS}

a Department of Psychiatry, University of Cambridge, School of Clinical Medicine, Cambridge Biomedical Campus, UK, CB2 OQQ

b Department of Clinical Neurosciences, University of Cambridge, Cambridge Biomedical Campus, Cambridge, CB2 0SZ

${ }^{c}$ Wolfson Brain Imaging Centre, University of Cambridge, UK, CB2 OQQ

${ }^{d}$ Cambridge University Hospitals NHS Foundation Trust, Cambridge, UK, CB2 0QQ

e Medical Research Council Cognition and Brain Sciences Unit, University of Cambridge, UK, CB2 7EF

\section{Corresponding Author:}

Dr Negin Holland MRCP, BSc

Association of British Neurologists Clinical Research Fellow University of Cambridge, Herschel Smith Building, Robinson Way, Cambridge, CB2 0SZ, UK; Tel: +441223764047; Nda26@cam.ac.uk

Abbreviations: PSP-RS=Progressive Supranuclear Palsy - Richardson's Syndrome. CBD = Corticobasal degeneration, PET= Positron Emission Tomography, NODDI= Neurite Orientation and Dispersion Imaging. 


\section{ABSTRACT}

Understanding the cellular underpinnings of neurodegeneration remains a challenge; loss of synapses and dendritic arborisation are characteristic and can be quantified in vivo, with $\left[{ }^{11} \mathrm{C}\right]$ UCB-J PET and MRI-based Orientation Dispersion Imaging (ODI), respectively. We aimed to assess how both measures are correlated, in 4R-tauopathies of Progressive Supranuclear Palsy (PSP-RS; $n=22$ ) and amyloid-negative (determined by $\left[{ }^{11} \mathrm{C}\right] \mathrm{PiB} P E T$ ) Corticobasal Degeneration (CBD; $n=14$ ), as neurodegenerative disease models, in this proof-of-concept study. Compared to controls $(n=27)$, PSP-RS and CBD patients had widespread reductions in cortical ODI, and $\left[{ }^{11} \mathrm{C}\right]$ UCB-J non-displaceable binding potential $\left(\mathrm{BP}_{\mathrm{ND}}\right)$ in excess of atrophy. In PSP-RS and CBD separately, regional cortical ODI was significantly associated with $\left[{ }^{11} \mathrm{C}\right] \cup C B-J \mathrm{BP}_{\mathrm{ND}}$ in disease-associated regions $(p<0.05$, FDR corrected). Our findings indicate that reductions in synaptic density and dendritic complexity in PSP-RS and CBD are more severe and extensive than atrophy. Furthermore, both measures are tightly coupled in vivo, furthering our understanding of the pathophysiology of neurodegeneration, and applicable to studies of early neurodegeneration with a safe and widely available MRI platform.

\section{Keywords (6)}

Neurodegeneration, $\left[{ }^{11}\right.$ C]UCB-J, PET, NODDI, tauopathy, synapse. 


\section{INTRODUCTION}

Abnormal dendritic morphology, and synaptic pathology are increasingly recognised as hallmarks of neurodegeneration, prior to cell death and atrophy, and correlate closely with cognitive dysfunction (Clare et al., 2010; DeKosky and Scheff, 1990; Herms and Dorostkar, 2016; Terry et al., 1991). However, quantification of synaptic pathology in vivo has until recently posed a challenge. Much of our knowledge about synaptic loss in neurodegeneration stems from animal and post mortem studies. For example, with frontotemporal lobar degeneration pathology (Coyle-Gilchrist et al., 2016) including Frontotemporal lobe Dementia (FTD), Progressive Supranuclear Palsy (PSP) and Corticobasal Degeneration (CBD), there is $30-50 \%$ loss of synapses, as determined by post mortem synaptophysin assays (Bigio et al., 2001; Lipton et al., 2001).

To quantify this pathophysiological change in vivo and uncover the early stages of neurodegeneration, would enable better design of clinical trials, accurate measurement of therapeutic response, and early intervention. In vivo cerebral glucose metabolism measured with $\left[{ }^{18} \mathrm{~F}\right] \mathrm{FDG}$ Positron Emission Tomography (PET), has often been interpreted as a synaptic density marker. Reductions are clinically relevant, for example, there are hippocampal reductions of $\left[{ }^{18} \mathrm{~F}\right] \mathrm{FDG}$ uptake in mild cognitive impairment (Mosconi et al., 2005) and reduced frontotemporal uptake in frontotemporal lobar degeneration (Blin et al., 1992; Juh et al., 2004); however, $\left[{ }^{18} \mathrm{~F}\right] \mathrm{FDG}$ is an indirect marker. In contrast, the recently, developed radioligand $\quad\left[{ }^{11} \mathrm{C}\right]$ UCB-J $\quad((R)-1-((3-($ methyl-11C)pyridin-4-yl)methyl)-4-(3,4,5trifluorophenyl)pyr-rolidin-2-one), allows direct quantification of synaptic density based on its affinity for the ubiquitously expressed presynaptic vesicle glycoprotein SV2A (Finnema et al., 2017,2016 ). This ligand shows up-to $40 \%$ loss of hippocampal synapses in patients with Alzheimer's disease (Chen et al., 2018), and a 20-50\% global reduction in PSP-RS/CBD (Holland et al., 2020) correlating with cognitive dysfunction. However, PET has limited scalability in diagnostics and trials, because of cost, specialist facilities required, and radiation limitations on repeated assessment.

Here we propose that with the loss of synapses, pre-synaptic vesicle density would correlate with changes in post-synaptic dendritic complexity. While diffusion tensor imaging (DTI) has proved to be a valuable non-invasive technique to probe microstructural white matter integrity, it has limited utility to characterise such changes in the cortex due to the isotropic water diffusion of the grey matter. Therefore, there is a need for biomarkers capable of evaluating functionally relevant microstructure noninvasively. To address the limitations of DTI, Neurite Orientation Dispersion Imaging (NODDI) is a multi-compartment biophysical 
diffusion imaging model that is capable of disentangling the diffusion signal arising from distinct tissue compartments, such as extracellular, intracellular water and cerebrospinal fluid (Zhang et al., 2012). This multi-compartmentalisation of the diffusion signal enables metrics such as Neurite Density Index (NDI) and Orientation Dispersion Index (ODI) to characterise the amount of neurites as well as the variability of neurite orientations respectively. Both the clinical feasibility and relevance of NODDI alterations have been successfully demonstrated in normal ageing and dementia (Cox et al., 2016; Slattery et al., 2017, 2015; Zhang et al., 2012). However, the biological substrates of NODDI are still unclear due to limited evidence of cross-validation among NODDI metrics and alternative proxies of grey matter microstructure. Recent studies have shown that NODDI Orientation Dispersion Index (ODI) is correlated with histologically-derived indices of neurite dispersion (Grussu et al., 2017; Schilling et al., 2018), highlighting its potential viability as a proxy of underlying biological changes in grey matter microstructure. Of particular relevance to our current study, reductions in cortical ODI has been found in a tau-transgenic mice model, entirely consistent with the severe extent of dendritic degeneration (Colgan et al., 2016). To the best of our knowledge, there has not been any attempt to characterise the coupling of cortical ODI with measurements of synaptic pathology (with $\left[{ }^{11} \mathrm{C}\right] U C B-J$ PET imaging). Compared to PET imaging, the ODI from NODDI would have the advantage of wide scalability in multicentre studies, repeatable assays without ionising radiation, and lower cost within a clinically feasible acquisition time ( 15 minutes).

In this proof-of-concept study, we focus on two rapidly progressive neurodegenerative tauopathies, progressive supranuclear palsy - Richardson's Syndrome (PSP-RS) and corticobasal degeneration (CBD) as disease models where grey matter atrophy although present, is not extensive unlike in Alzheimer's disease where we would expect generalised atrophy; this allows us to examine cortical microstructure without the influence of atrophy. Pathologically, both PSP-RS and CBD are associated with accumulation of both cortical and subcortical 4-repeat tau (Dickson et al., 2011; Kovacs et al., 2020; Rösler et al., 2019; Schofield et al., 2012), and clinically present with a movement disorder (Armstrong et al., 2013; Höglinger et al., 2017; Litvan et al., 1996) and cognitive decline (Burrell et al., 2014). Both conditions are associated with cortical and subcortical atrophy (Jabbari et al., 2019) but we have previously shown significant widespread presynaptic loss extending beyond atrophic areas (Holland et al., 2020) concordant with findings from studies utilising electromagnetoencephalography where impairment in cortical physiology is seen in both atrophic and minimally atrophic regions (Cope et al., 2018; Hughes et al., 2014; Sami et al., 2018). Having illustrated presynaptic loss as a potential explanation for impairment in cortical physiology, we aimed to investigate the synaptic bouton at large by also focusing on 
the post-synaptic compartment, by utilising a non-invasive MRI method such as ODI, as an index of dendritic complexity.

There is a very high clinicopathological correlation between 4R-tauopathy and the classical presentation of PSP-RS-Richardson's syndrome. The clinical spectrum of CBD is diverse; the pathology of CBD is a major cause of the corticobasal syndrome (CBS), which is often mimicked by Alzheimer's disease or sometimes PSP-RS pathology (Alexander et al., 2014). For this reason, CBD generally refers to the pathology and CBS to the clinical syndrome. This strategy reduces the likelihood of mixing amyloid pathology from Alzheimer's disease with the primary 4R-tauopathy of PSP-RS and CBD. We therefore infer that patients with CBS in whom Alzheimer's disease is excluded (with $\left[{ }^{11} \mathrm{C}\right] \mathrm{PiB} P E T$ ) have probable CBD, but acknowledge that other pathologies are also likely.

We test the hypothesis that the functionally relevant loss of pre-synaptic density caused by PSP-RS and CBD is correlated to the changes in post-synaptic dendritic complexity, independent of changes in grey matter atrophy.

\section{MATERIALS AND METHODS}

\subsection{Experimental design}

Patients were recruited from the Cambridge tertiary neurology clinic with for PSP-RS and CBS/CBD. Healthy volunteers were recruited from the UK National Institute for Health Research Join Dementia Research (JDR) register. Patients had either probable PSP-RSRichardson Syndrome (Höglinger et al., 2017) , or CBS with possible/probable CBD (Armstrong et al., 2013). Participants underwent a clinical and cognitive assessment including measures of disease severity (Table 1), 3T MRI, and $\left[{ }^{11} \mathrm{C}\right] \mathrm{UCB}-\mathrm{J}$ PET. Patients with CBD underwent amyloid PET imaging using Pittsburgh Compound $\mathrm{B}\left(\left[{ }^{11} \mathrm{C}\right]-\mathrm{PiB}\right)$. Only those with a negative amyloid status are included in the subsequent analysis, as determined by a $\left[{ }^{11} \mathrm{C}\right]-\mathrm{PiB}$ standardised uptake value ratio (SUVR; 50-70 minutes post injection; whole cerebellum reference tissue) less than 1.21 (Centiloid scale 19 (Jack et al., 2017)); on this basis 12 out of 26 CBS patients were excluded. The research protocol was approved by the Cambridge Research Ethics Committee and the Administration of Radioactive Substances Advisory Committee. All participants provided written informed consent in accordance with the Declaration of Helsinki. 


\subsection{Neuroimaging processing}

\subsubsection{T1-weighted MRI}

T1-MPRAGE was acquired on the Siemens Magnetom 3T PRISMA scanner (TE $=2.93 \mathrm{~ms}$, $\mathrm{TR}=2 \mathrm{~s}$, slice thickness $=1.1 \mathrm{~mm}$, resolution $=1.1 \mathrm{~mm}^{3}$ isotropic, 208 slices). The data were processed using Computational Anatomy Toolbox in SPM12. The T1-MPRAGE images were then segmented into grey matter, white matter, and CSF images by using a unified tissue segmentation technique after image intensity non-uniformity correction was performed. Regional cortical thickness was derived in CAT12 based on the projection-based thickness method (Dahnke et al., 2013), which uses topology correction. (Yotter et al., 2011a) and spherical mapping (Yotter et al., 2011b). Previous studies have shown that CAT12 produce reliable estimates of cortical thickness, yielding larger effect sizes in casecontrol comparisons (Seiger et al., 2018). All segmentations were visually inspected by 3 authors (E.M, A.L. and M.M). 3 PSP-RS subjects were excluded due to sub-optimal contrast between grey and white matter tissue, resulting in unsatisfactory segmentations.

\subsubsection{Diffusion-weighted $M R I$}

Diffusion scans were acquired on Siemens Magnetom Prisma scanner (TE $=75.6 \mathrm{~ms}$, TR $=$ $2.4 \mathrm{~s}$, slice thickness $=1.75 \mathrm{~mm}, 98$ directions, 104 slices, bvals $=300,1000,2000$ ). Diffusion datasets were pre-processed with FSL-FDT (FMRIB's Diffusion Toolbox). Firstly, the DWI data were stripped of nonbrain tissue using the Brain Extraction Tool. The resulting brain masks were visually inspected for anatomic fidelity. Eddy currents and head movements were corrected with "eddy" in FSL (Version 6.0.1). TOPUP was applied to correct for estimating and correcting susceptibility induced distortions. The b0 volume from the reversed phase-encode blip was used in TOPUP for the estimation and correction of susceptibility induced distortion. Quantitative identification of slices with signal loss was performed in "eddy" and these volumes were replaced by non-parametric predictions using the Gaussian process (Andersson et al., 2016). The b-matrix was subsequently reoriented by applying the rotational part of the affine transformation used during eddy correction (Leemans and Jones, 2009). Next, ODI maps were derived from the eddy-corrected datasets using the Microstructural Diffusion Toolbox (MDT) (Harms et al., 2017). There has been recent debate over the validity of NODDI's assumption of a fixed intrinsic diffusivity across the brain, especially in the grey matter. Therefore, to optimise analyses of ODI, we set the intrinsic diffusivity to $1.1(0.1) \times 10^{-3} \mathrm{~mm}^{2} / \mathrm{s}$ as previously proposed (Fukutomi et al., 2018; Genç et al., 2018).

\subsubsection{Positron Emission Tomography (PET)}


A subset of patients underwent dynamic PET imaging (Controls $=19, \mathrm{PSP}-\mathrm{RS}=20, \mathrm{CBD}=$ 12) on a GE SIGNA PET/MR (GE Healthcare, Waukesha, USA) for 90 minutes starting immediately after $\left[{ }^{11} \mathrm{C}\right]$ UCB-J injection (median injected activity: $351 \pm 107 \mathrm{MBq}$, injected mass $\leq 10 \mu \mathrm{g}$ ), with attenuation correction including the use of a multi-subject atlas method (Burgos et al., 2014; Prados et al., 2016) and also improvements to the MRI brain coil component (Manavaki et al., 2019). Each emission image series was aligned using SPM12 (www.fil.ion.ucl.ac.uk/spm/software/spm12/) to ameliorate the effect of patient motion, then rigidly registered to a $\mathrm{T} 1$-weighted $\mathrm{MRI}$ acquired during PET data. To quantify SV2A density, parametric maps of $\left[{ }^{11} \mathrm{C}\right]$ UCB-J non-displaceable binding potential $\left(\mathrm{BP}_{\mathrm{ND}}\right)$ was determined using a basis function implementation of the simplified reference tissue model $\mathrm{Wu}$ and Carson, 2002), with the reference tissue defined in the centrum semiovale (Koole et al., 2019; Rossano et al., 2019).

\subsubsection{Extraction of regional measurements from $T 1, O D I$ and $\left[{ }^{11} C\right] U C B-J B P_{N D}$}

ODI and $\left[{ }^{11} \mathrm{C}\right]$ UCB-J maps were coregistered to the skull-stripped T1 brain image using rigid registrations in Advance Normalisation Tools (ANTS; http://stnava.github.io/ANTs/). The accuracy of all coregistrations was visually inspected. The coregistered ODI and $\left[{ }^{11} \mathrm{C}\right] \mathrm{UCB}-\mathrm{J}$ volumes were projected to the surface for cortical analyses. To that end, we applied a weighted-mean method that uses a Gaussian kernel for mapping along the normal, based on the recommended settings in CAT12. Finally, ROI extraction was performed within the surface space using the Desikan Killiany atlas. We used a modified Hammers atlas to extract measurements from the subcortical regions and midbrain. The atlas was subsequently transposed into the native spaces of ODI and $\left[{ }^{11} \mathrm{C}\right] \mathrm{UCB}-\mathrm{J}$ respectively using the inverse of transformations from the coregistrations between ODI or $\left[{ }^{11} \mathrm{C}\right] \mathrm{UCB}-\mathrm{J}$ and T1 MPRAGE. Mean regional ODI, $\left[{ }^{11} \mathrm{C}\right]$ UCB-J and grey matter volumes were extracted using fs/stats in FSL. Finally, each subject has the following imaging measurements: regional cortical thickness, cortical ODI, cortical $\left[{ }^{11} \mathrm{C}\right]$ UCB-J $\mathrm{BP}_{\mathrm{ND}}$, as well as subcortical and midbrain grey matter volumes, ODI and $\left[{ }^{11} \mathrm{C}\right] \mathrm{UCB}-\mathrm{J}$ BP $\mathrm{ND}$.

\subsection{Statistical Analysis}

We used $R$ to compare demographic variables between the diagnostic groups using ANOVA, Kruskal Wallis and chi-square tests where appropriate. To investigate regional group differences of grey matter, ODI and $\left[{ }^{11} \mathrm{C}\right] \mathrm{UCB}-\mathrm{J} \mathrm{BP}_{\mathrm{ND}}$, we used non-parametric permutation-based inference, implemented using Permutation Analysis of Linear Models (PALM; https://fsl.fmrib.ox.ac.uk/fsl/fslwiki/PALM) in MATLAB, adjusted for age (5000 permutations) (Winkler et al., 2014). A key advantage of permutation-based approach is the robustness of statistics to heteroscedasticity and its minimal assumptions on data 
distributions. Next, non-parametric permutation tests for Biological Parametric Mapping (BPM) were used to assess whole-brain inter-regional associations between ODI and $\left[{ }^{11} \mathrm{C}\right]$ UCB-J $\mathrm{BP}_{\mathrm{ND}}$ across the patient sample, as well as within CBS and PSP-RS groups separately. Correlational analyses were adjusted for age and local grey matter thickness / volume. Statistical results were adjusted using the False Discovery Rate (FDR) correction across the cortical, subcortical regions and the midbrain (81 ROIs). Mean values, standard deviations, $\mathrm{P}$ values and Cohen's $\mathrm{D}$ were overlaid on 2D brain templates using the ggseg package in $\mathrm{R}$ (Mowinckel and Vidal-Piñeiro, 2019). The derived data that support the findings of this study are available from the corresponding author, upon reasonable request for academic (non-commercial) purposes.

\section{RESULTS}

\subsection{Demographics}

Clinical and demographic information are summarised in Table 1. Patients and controls were matched in age and gender although education years were significantly lower in PSPRS relative to controls (Post-hoc Dunn's Test after Kruskal-Wallis test; $p<0.001$ ). Patients with PSP-RS and CBD had lower total ACE-R scores compared to controls $(p<0.001)$.

\begin{tabular}{|c|c|c|c|c|}
\hline & $\begin{array}{l}\text { Control } \\
(\mathrm{N}=27)\end{array}$ & $\begin{array}{c}\text { CBD } \\
(\mathrm{N}=14)\end{array}$ & $\begin{array}{c}\text { PSP-RS } \\
(\mathrm{N}=22)\end{array}$ & $\mathbf{P}$ \\
\hline \multicolumn{5}{|l|}{ Age (years) } \\
\hline Mean (SD) & $69.0(7.34)$ & $70.0(7.91)$ & $70.9(8.69)$ & 0.715 \\
\hline Median [Min, Max] & $72.0[52.0,84.0]$ & $70.0[58.0,87.0]$ & $73.0[51.0,85.0]$ & \\
\hline \multicolumn{5}{|l|}{ Gender } \\
\hline Female & $11(40.7 \%)$ & $5(35.7 \%)$ & $12(54.5 \%)$ & 0.474 \\
\hline Male & $16(59.3 \%)$ & $9(64.3 \%)$ & $10(45.5 \%)$ & \\
\hline \multicolumn{5}{|l|}{ Education (years) } \\
\hline Mean (SD) & $14.9(3.65)$ & $12.4(3.03)$ & $12.1(4.33)$ & 0.005 \\
\hline Median [Min, Max] & $16.0[10.0,22.0]$ & $12.0[7.00,18.0]$ & $11.0[9.00,29.0]$ & \\
\hline \multicolumn{5}{|l|}{ ACER } \\
\hline Mean (SD) & $95.9(3.81)$ & $78.2(18.9)$ & $80.4(12.7)$ & $<0.001$ \\
\hline Median [Min, Max] & $97.0[83.0,100]$ & $83.0[24.0,95.0]$ & $81.5[37.0,97.0]$ & \\
\hline \multicolumn{5}{|l|}{ PSPRS } \\
\hline Mean (SD) & $0.148(0.534)$ & $26.9(7.88)$ & $33.3(9.86)$ & $<0.001$ \\
\hline Median [Min, Max] & $0[0,2.00]$ & $27.0[12.0,45.0]$ & $33.5[14.0,52.0]$ & \\
\hline
\end{tabular}


medRxiv preprint doi: https://doi.org/10.1101/2020.12.24.20248838; this version posted December 27, 2020. The copyright holder for this preprint (which was not certified by peer review) is the author/funder, who has granted medRxiv a license to display the preprint in perpetuity.

It is made available under a CC-BY 4.0 International license .

Table 1. Demographics and clinical variables. Abbreviations: $C B D=$ Corticobasal Degeneration defined as amyloid negative corticobasal syndrome, PSP-RS = Progressive Supranuclear Palsy Richardson's syndrome, PSPRS = Progressive Supranuclear Palsy Rating Scale; ACER = Addenbrooke's Cognitive Examination-Revised. Parameters are expressed as mean \pm standard deviation (SD). $\mathrm{P}$ values are shown for analysis of variance across groups or chi-squared test as appropriate. 


\subsection{Group comparisons of grey matter atrophy, ODI and $\left[{ }^{11} \mathrm{C}\right] \mathrm{UCB}-\mathrm{J}$ BP $\mathrm{ND}$}

For all groups, mean \pm standard deviation (SD) distributions of regional cortical thickness, subcortical grey matter volumes, ODI and $\left[{ }^{11} \mathrm{C}\right] \mathrm{UCB}-\mathrm{J} \mathrm{BP}_{\mathrm{ND}}$ are overlaid on brain templates in Figure 1 and Figure 2. Permutation-based statistical comparisons across all imaging measurements are reported for PSP-RS and CBD relative to controls, adjusted for age and FDR corrected in Figure 3 and Figure 4.

\subsubsection{Progressive supranuclear palsy - Richardson's Syndrome}

Statistical results and corresponding effect sizes from the comparisons between PSP-RS and controls illustrated in Figure 3A-C. Non-parametric permutation-based tests showed that, relative to controls, the PSP-RS group exhibited significant cortical thinning particularly in the motor cortex and frontal cortices; subcortical atrophy was found in the thalamus, putamen and pallidum and midbrain. In PSP-RS, significant reductions in cortical ODI were more widespread than areas affected by atrophy, including multiple areas within the cortical mantle and also subcortically including the basal ganglia. Post-hoc paired T-Tests of the regional Fisher's transformed Cohen's D indicated that the regional effect sizes were significantly larger for ODI compared to grey matter atrophy (Figure $3 \mathrm{C}$ ). As expected, the PSP-RS group showed extensive and severe reductions of $\left[{ }^{11} \mathrm{C}\right] \mathrm{UCB}-\mathrm{J}$ BP $\mathrm{ND}_{\mathrm{ND}}$ across the cortex and subcortical regions compared to controls, replicating our previous findings in a smaller sample (Holland et al., 2020). Across the whole brain, reductions in [ $\left.{ }^{11} \mathrm{C}\right]$ UCB-J $B P_{\mathrm{ND}}$ yielded the largest effect size relative to both ODI and grey matter atrophy.

\subsubsection{Corticobasal Degeneration}

Statistical results and corresponding effect sizes from the comparisons between CBD and controls are illustrated in Figure 4A-C. Relative to controls, the CBD group showed focal cortical thinning in motor cortex, superior frontal cortex and the occipital lobe, as well as atrophy in the left putamen and bilateral pallidum. In contrast, widespread ODI reductions were found extending beyond the atrophy-affected motor cortices to other regions that were relatively preserved from atrophy, notably the temporo-parietal and cingulate cortices. In addition, there was bilateral significant ODI reductions in the caudate and putamen, both of which showed no significant grey matter atrophy. Accordingly, regional Cohen's D of ODI was significantly larger than that of grey matter atrophy (Figure $4 \mathrm{C}$ ). Finally, $\left[{ }^{11} \mathrm{C}\right] \mathrm{UCB}-\mathrm{J}$ $\mathrm{BP}_{\mathrm{ND}}$ comparisons revealed a generalised and widespread extent of significantly reduced $\left[{ }^{11} \mathrm{C}\right]$ UCB-J BP $\mathrm{ND}$ across the cortex and subcortical regions compared to controls. 


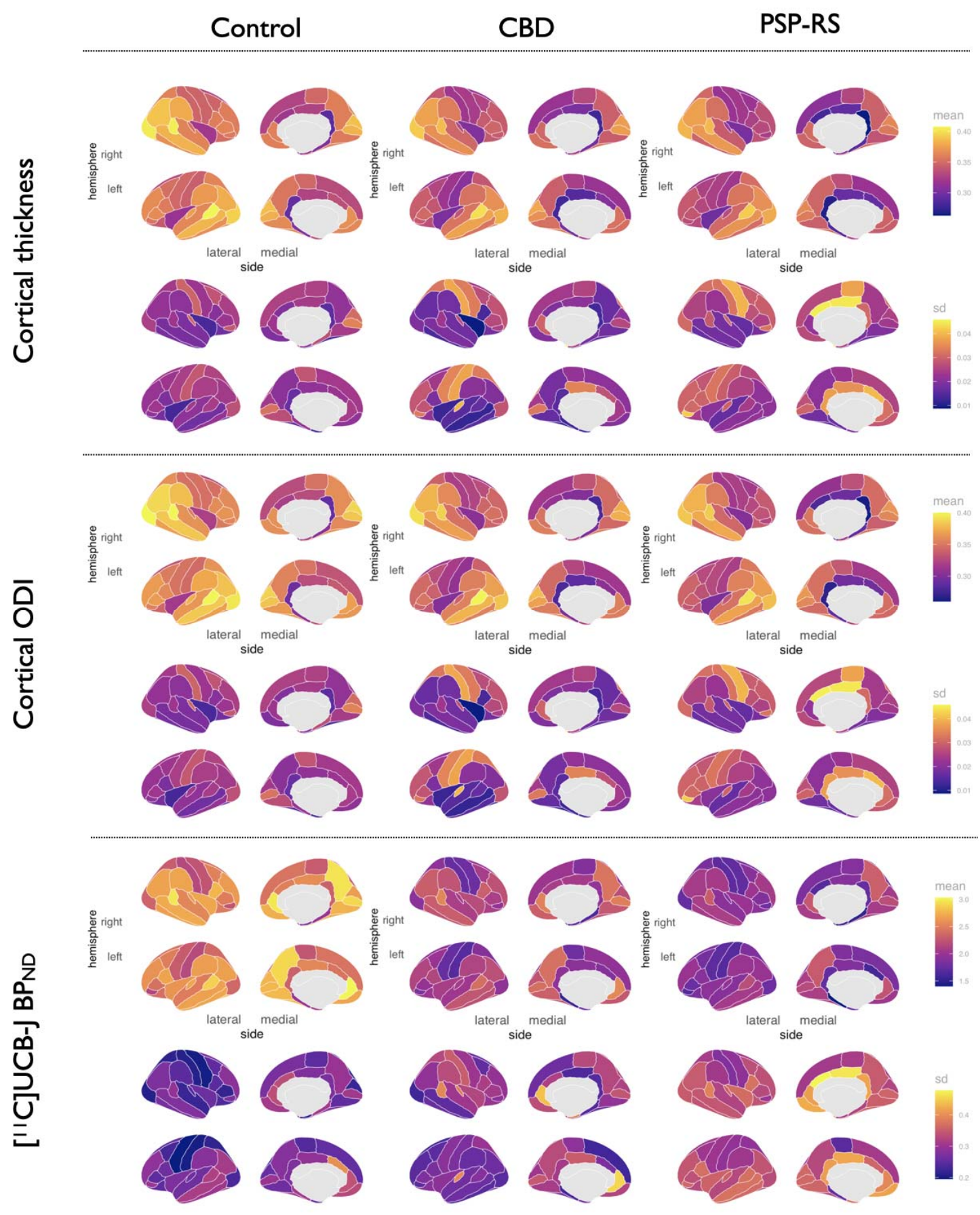

Figure 1. Regional distributions of cortical thickness, cortical ODI and cortical $\left[{ }^{11} \mathrm{C}\right]-$

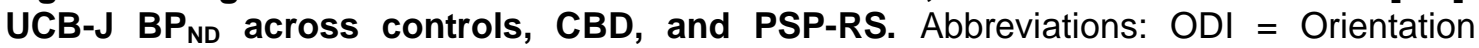
Dispersion Index, CBD = amyloid negative Corticobasal Syndrome; PSP-RS = Progressive Supranuclear Palsy-Richardson's Syndrome; sd = Standard deviation. 


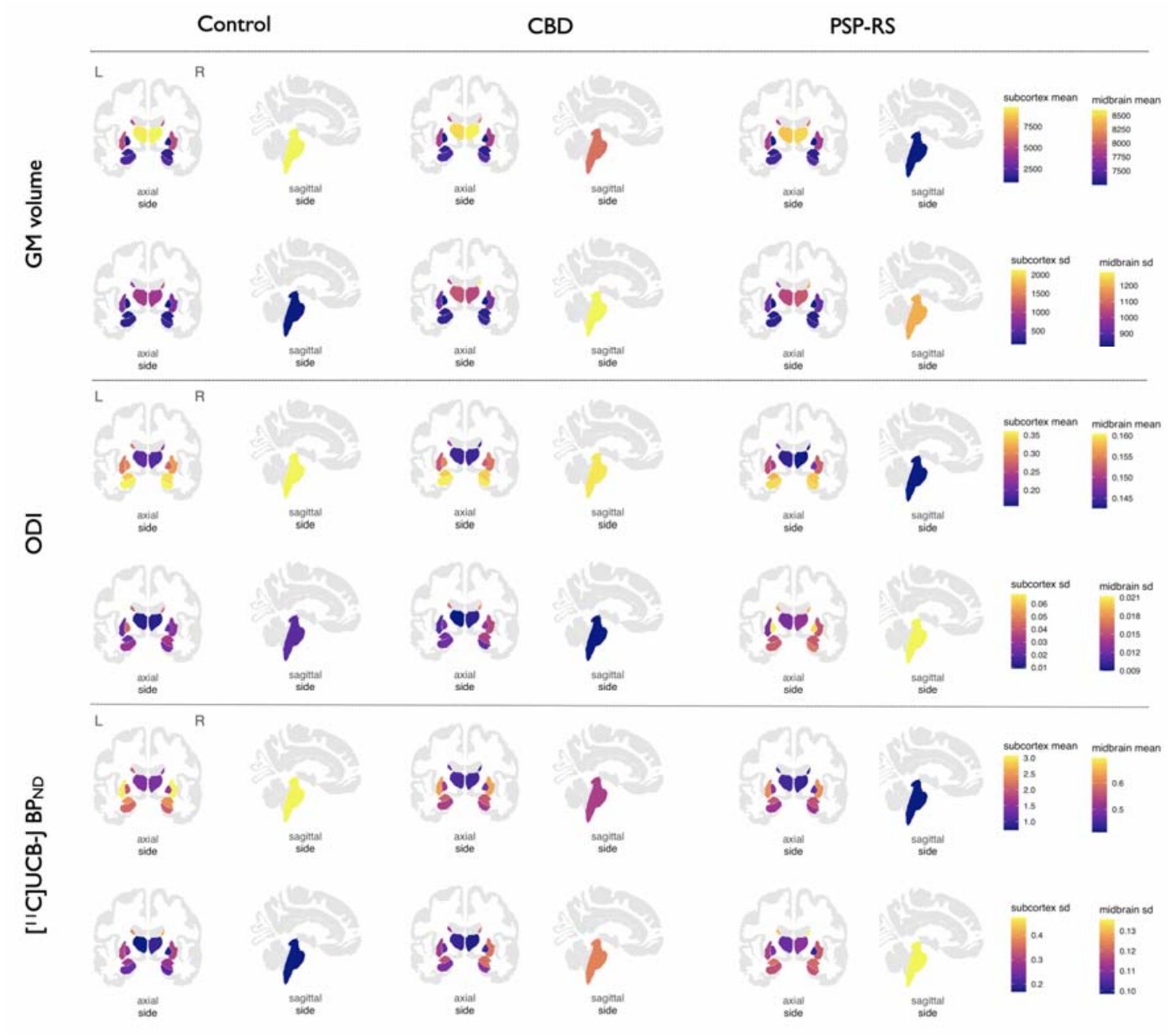

Figure 2. Subcortical distributions of grey matter volumes, ODI and $\left[{ }^{11} \mathrm{C}\right]-\mathrm{UCB}-\mathrm{J} \mathrm{BP}_{\mathrm{ND}}$ across controls, CBD, and PSP-RS. Abbreviations: ODI = Orientation Dispersion Index, $\mathrm{CBD}=$ amyloid negative Corticobasal Syndrome; PSP-RS = Progressive Supranuclear Palsy-Richardson's Syndrome; sd = standard deviation; GM = grey matter. For ease of visualisation the colours in the brainstem represent the midbrain only. 
A
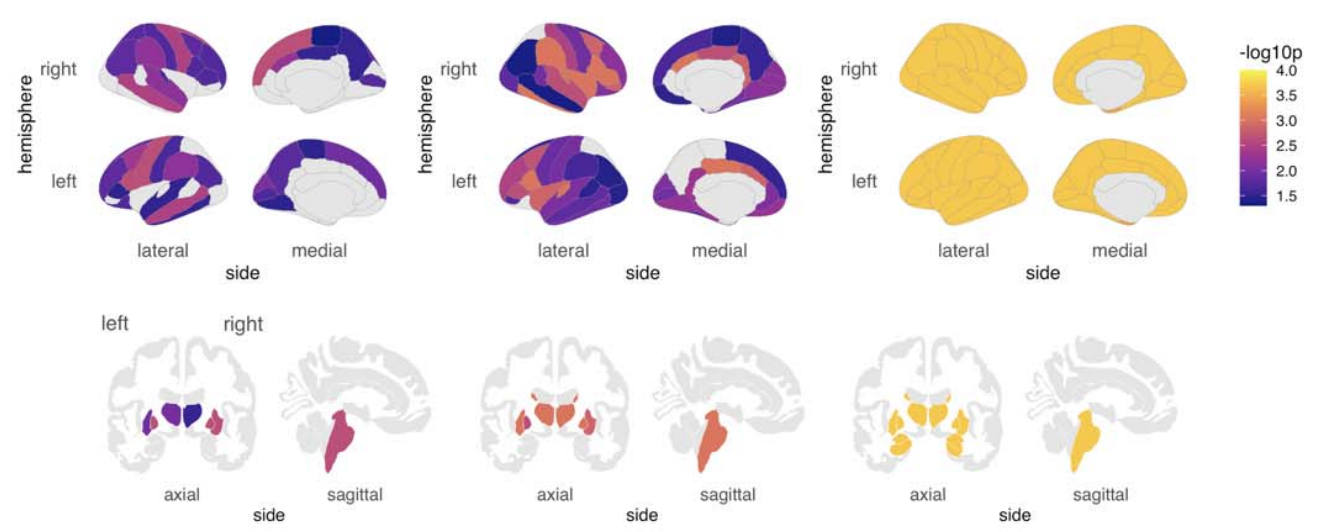

B
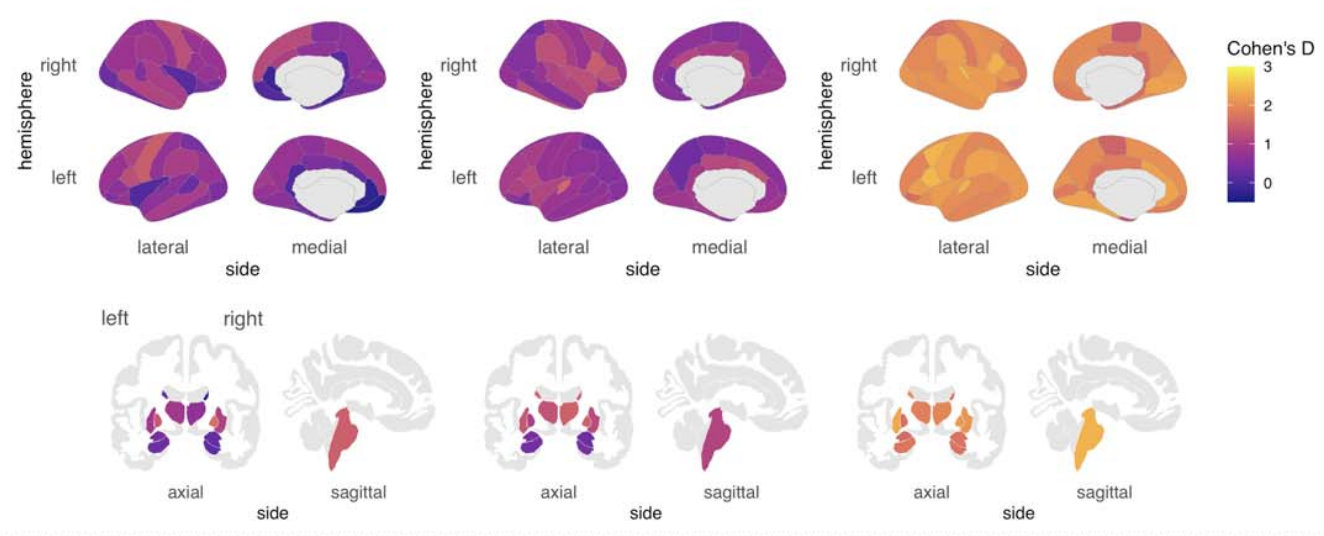

\section{C}
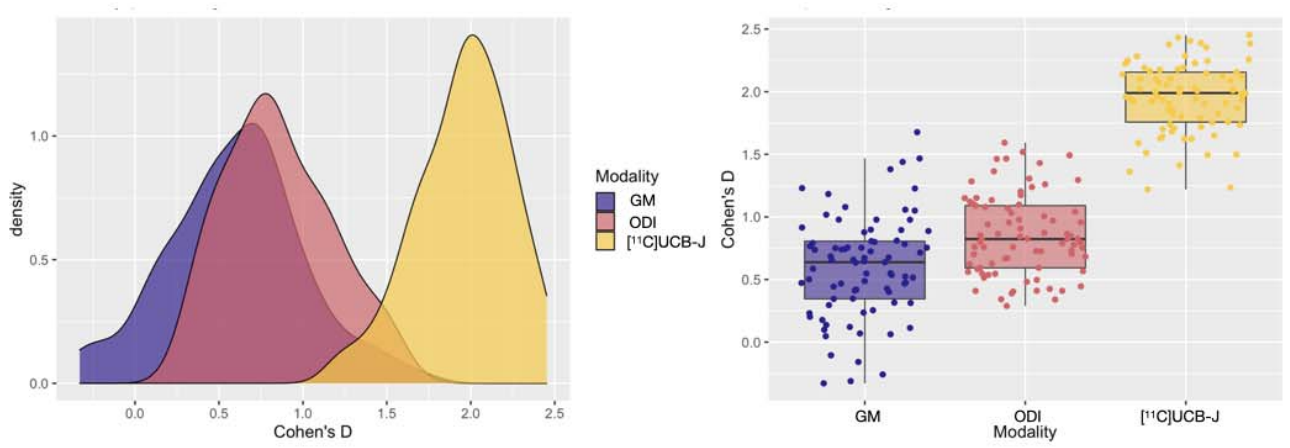

Figure 3. GM atrophy, reduced ODI and [ $\left.{ }^{11} \mathrm{C}\right]$ UCB-J $\mathrm{BP}_{\mathrm{ND}}$ in PSP-RS vs Controls. A: Pvalues of regions surviving FDR correction are visualised on cortical and subcortical brain templates. B: Density plots of distributions of effect sizes. C: Boxplots of effect sizes of grey matter atrophy, ODI and $\left[{ }^{11} \mathrm{C}\right] \cup C B-J B_{N D}$ from the group comparisons. Abbreviations: ODI = Orientation Dispersion Index; PSP-RS = Progressive Supranuclear Palsy-Richardson's Syndrome;

$\mathrm{FDR}=$ False

Discovery

Rate;

GM

$=$ grey

matter. 


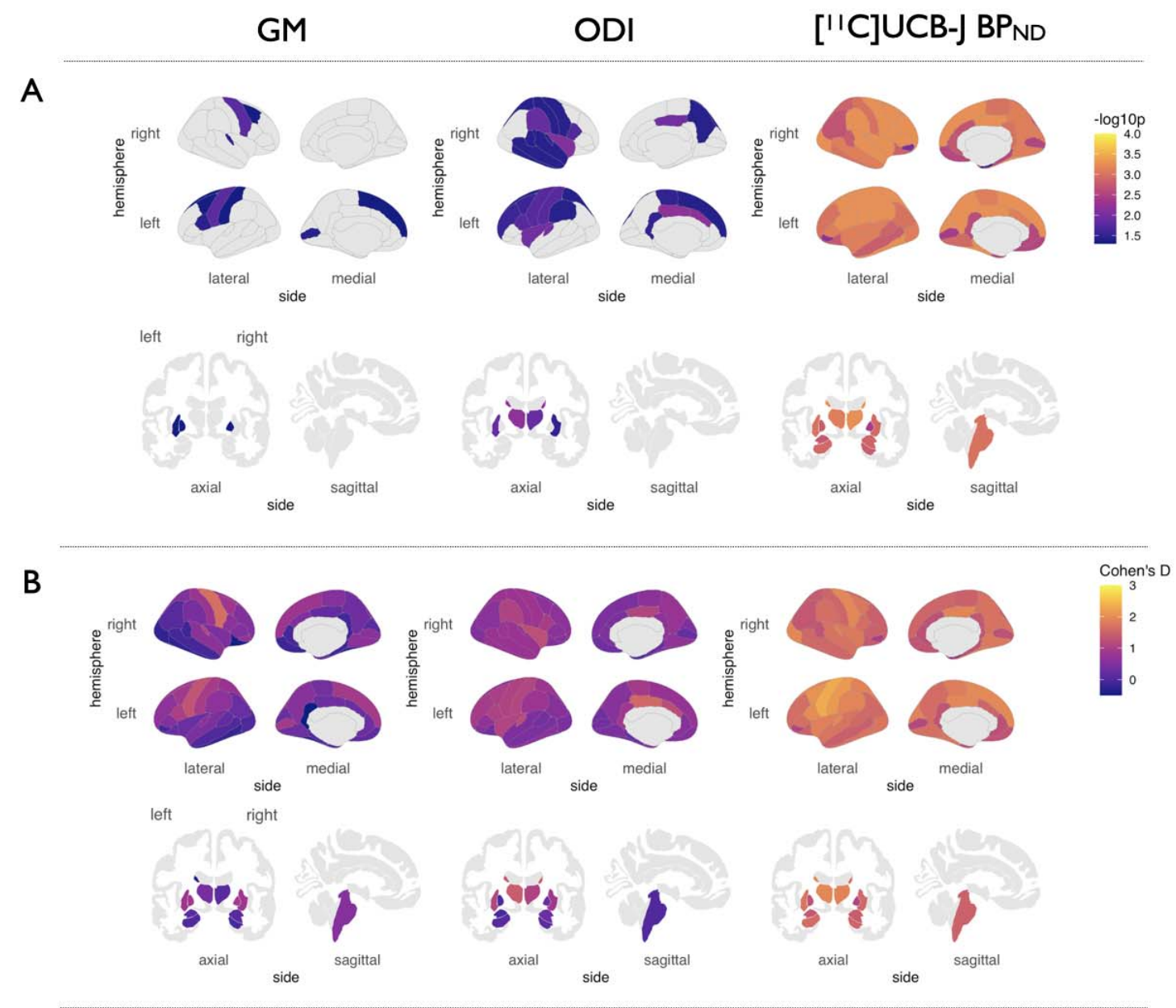

\section{C}
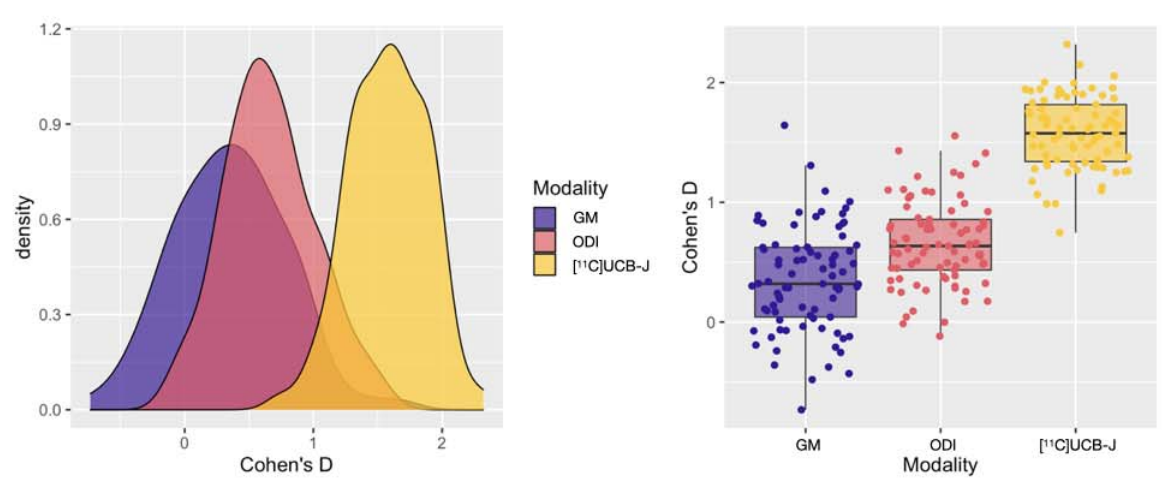

Figure 4. GM atrophy, reduced ODI and $\left[{ }^{11} \mathrm{C}\right] \mathrm{UCB}-\mathrm{J} \mathrm{BP}_{\mathrm{ND}}$ in $\mathrm{CBD}$ vs Controls. A: Pvalues of regions surviving FDR correction are visualised on cortical and subcortical brain templates. B: Density plots of distributions of effect sizes. C: Boxplots of effect sizes of grey matter atrophy, $\mathrm{ODI}$ and $\left[{ }^{11} \mathrm{C}\right] \mathrm{UCB}-\mathrm{J} \mathrm{BP}_{\mathrm{ND}}$ from the group comparisons. Abbreviations: ODI = Orientation Dispersion Index; FDR = False Discovery Rate; GM = grey matter; $\mathrm{CBD}=$ amyloid negative Corticobasal Syndrome. 


\subsection{Regional associations of ODI with [ $\left.{ }^{11} \mathrm{C}\right] \mathrm{UCB}-\mathrm{J} \mathrm{BP}_{\mathrm{ND}}$}

Non-parametric permutation models were used to assess the inter-regional associations between $\mathrm{ODI}$ and $\left[{ }^{11} \mathrm{C}\right] \mathrm{UCB}-\mathrm{J} \mathrm{BP}_{\mathrm{ND}}$ across the full patient sample, while sensitivity analyses were conducted for PSP-RS and CBD groups separately. To visualise the spatial patterns of these regional correlations, accounting for age and regional grey matter atrophy, we projected the $p$ values on brain templates (Figure 5). Within the total sample of CBD and PSP-RS patients, multiple cortical and subcortical regions demonstrated local positive associations where $\left[{ }^{11} \mathrm{C}\right]$ UCB-J $\mathrm{BP}_{\mathrm{ND}}$ locally predicted ODI, i.e. across subjects, both presynaptic density and dendritic arborisation showed reciprocal associations within the same region (Figure 5A). Scatter plots for each significant local association are shown in Supplementary Figure 1. The regions showing the strongest correlations between ODI and $\left[{ }^{11} \mathrm{C}\right]$ UCB-J $\mathrm{BP}_{\mathrm{ND}}$ were primarily in bilateral pre and postcentral gyri and the prefrontal cortex, but also extended to subcortical areas including the basal ganglia, thalamus and the midbrain. When the analyses were restricted to the CBD sample, the spatial extent of local associations was markedly attenuated, although significant associations were still present within the bilateral pre and post central gyri, and isolated regions in the frontal and occipital lobe (Figure 5B). Within the PSP-RS group, $\left[{ }^{11} \mathrm{C}\right] \mathrm{UCB}-\mathrm{J} \mathrm{BP}_{\mathrm{ND}}$ was significantly correlated with ODI in a widespread spatial pattern similar to that of the total sample. Peak correlations were identified within the motor cortex and cingulate regions (Figure $\mathbf{5 C}$ ), but also included the thalami, midbrain and parts of the basal ganglia. These analyses did not include the control group and is thus not indicative of a group effect. Nevertheless, to determine the specificity of the coupling between $\mathrm{ODI}$ and $\left[{ }^{11} \mathrm{C}\right] \mathrm{UCB}-\mathrm{J} \mathrm{BP}_{\mathrm{ND}}$, we ran the same nonparametric permutation model on the controls, accounting for age and regional grey matter atrophy. This analysis did not yield any significant local associations that retained statistical significance after FDR correction. 




II

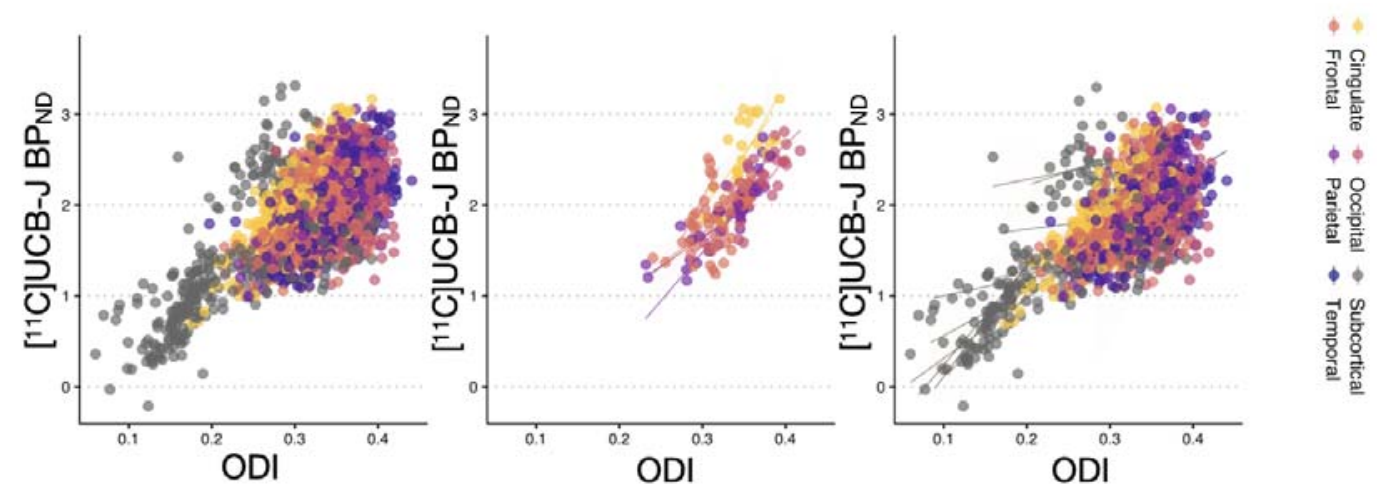

Figure 5. Local associations between ODI and [ $\left.{ }^{11} \mathrm{C}\right] \mathrm{UCB}-\mathrm{J} \mathrm{BP}_{\mathrm{ND}}$ in $(\mathrm{A})$ total sample of patients, (B) CBD and (C) PSP-RS separately. I: Statistical $p$ values for regions surviving FDR correction are overlaid on cortical and subcortical brain templates. II: Scatter plots showing the relationships between ODI and $\left[^{11} \mathrm{C}\right] \mathrm{UCB}-\mathrm{J} B \mathrm{P}_{\mathrm{ND}}$ for all regions surviving FDR correction, coloured by lobes and subcortex. Abbreviations: ODI = Orientation Dispersion Index. PSP-RS = Progressive Supranuclear Palsy-Richardson's Syndrome; CBD = amyloid negative Corticobasal Syndrome. 


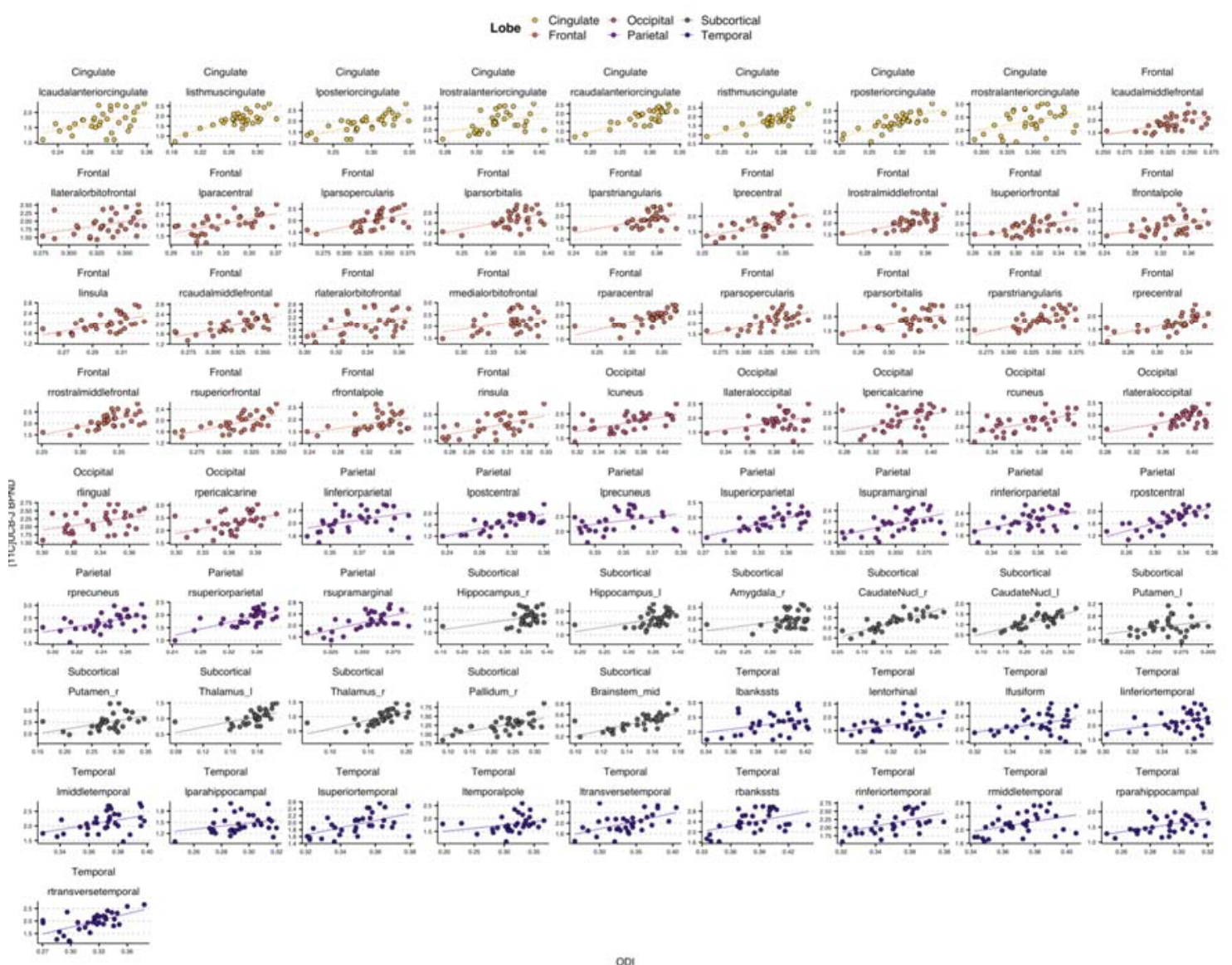

Supplementary Figure 1. Significant local associations between cortical ODI and $\left[{ }^{11} \mathrm{C}\right] \mathrm{UCB}-\mathrm{J} B \mathrm{P}_{\mathrm{ND}}$ in PSP-RS and CBD patients (FDR $\mathrm{p}<0.05$, after adjusting for age and local GM atrophy). Abbreviation: ODI = Orientation Dispersion Index; FDR = False Discovery Rate; GM = Grey Matter. 


\section{DISCUSSION}

This study tested the hypothesis that changes in synaptic density are closely linked to MRI measures of cortical microstructure, in the neurodegenerative tauopathies of CBD and PSPRS. The main insights are that (i) in the neurodegenerative tauopathies of Corticobasal Degeneration (CBD) and Progressive Supranuclear Palsy (PSP-RS), widespread changes in grey matter dendritic complexity are observed even in areas without significant atrophy; and (ii) Orientation Dispersion Imaging (ODI), an MRI-based estimate of post-synaptic dendritic structure and complexity, correlates with the loss of presynaptic density estimated by the PET radioligand $\left[{ }^{11} \mathrm{C}\right] \mathrm{UCB}-\mathrm{J}$; this effect is not a result of changes in grey matter atrophy. This extends previous investigations of ODI microstructural change in PSP-RS and CBS/CBD (Mitchell et al., 2019), demonstrating the in vivo coupling of dendritic complexity to presynaptic density, in line with preclinical models of tauopathies (Hoffmann et al., 2014; Rocher et al., 2010).

Grey matter atrophy within the motor cortex, as well as the basal ganglia and brainstem are common MRI findings in PSP-RS and CBD; the pattern of atrophy shown in figure 1 and 2 concords with previous studies (Jabbari et al., 2019). In this study however we show that, both within areas of the brain where there is atrophy, and in areas with absent atrophy, there is significant and more severe loss of dendritic complexity and, as previously shown (Holland et al., 2020) and replicated here, presynaptic density in the patient cohort. The widespread pattern of cortical ODI and presynaptic deficits in PSP-RS and CBD matches the expected pattern of tau pathology, both in the subcortical and cortical area (Dickson et al., 2011; Kovacs et al., 2020). Loss of dendritic complexity and presynaptic loss, in non-atrophied areas of the brain, for example the occipital lobes, potentially reflects early changes in synaptic function, in response to tau pathology (Kovacs et al., 2020), or toxic oligomers of tau, that later in the disease process progress to atrophy. Indeed, in preclinical models, pathological tau oligomers induce synaptic degeneration (Usenovic et al., 2015) and interfere with synaptic function and density (Yoshiyama et al., 2007), in the absence of neuronal loss.

The effect size for the comparison between ODI and $\left[{ }^{11} \mathrm{C}\right] \mathrm{UCB}-\mathrm{J} \mathrm{BP}_{\mathrm{ND}}$ in patients relative to controls, was stronger than for atrophy. Together, the larger extent of ODI reductions relative to grey matter atrophy indicate that NODDI can reveal new aspects of the cellular pathology of tauopathies, in keeping with the recent demonstration that changes in ODI parameters closely reflect complex histological changes (Grussu et al., 2017). Notwithstanding the cross-sectional design of this study, this observation highlights the early structural changes in disease pathogenesis that may underlie the emergence of cognitive and motor symptoms 
not attributable to atrophy. Indeed studies of cortical physiology in PSP-RS have illustrated abnormal electrophysiology in the absence of atrophy (Hughes et al., 2013; Sami et al., 2018). Our findings of reduced ODI beyond atrophy are in agreement with those published from the Alzheimer's disease literature (Parker et al., 2018) which is a related tauopathy to PSP-RS and CBD, where there is a stronger relationship between cognitive function and synaptic density than with atrophy (Terry et al., 1991).

Our observation of a tight coupling between dendritic complexity (figure 3 and 4), as measured with ODI, and presynaptic density, as measured with $\left[{ }^{11} \mathrm{C}\right] \mathrm{UCB}-\mathrm{J}$, in the patient cohort, echo preclinical findings in animal models of tauopathy (Harris and Kater, 1994), and post mortem studies (Bigio et al., 2001; Lipton et al., 2001). There are two potential explanation for this tight coupling: first, tau protein is enriched in axons and associated with axonal growth and transport; the synaptic toxicity associated with pathological tau is observed both in pre- and post-synaptic structures (see review by Mang \& Mendelkow 2015 (Wang and Mandelkow, 2016)), leading to both a reduction in dendritic complexity and presynaptic density. Second, while a cross-sectional design precludes inferences of causality, alterations in synaptic function in CBD and PSP-RS (Holland et al., 2020) are expected to induce dendritic morphological alterations with early loss of dendritic spines and reduced dendritic branching. This has been illustrated in animal studies, where post-synaptic dendritic morphology correlates with the numbers of presynaptic vesicles and synaptic strength (Schikorski and Stevens, 1999). It is possible that primary dendritic degeneration in CBD and PSP-RS causes a reduction in the density of the presynaptic contacts on the distal dendrites. These alternative accounts are not mutually exclusive and could act in parallel to impair effective transneuronal connectivity, and subsequently motor and cognitive function.

The downstream effect of the above is a loss of functional connectivity. Indeed in PSP-RS there is reduced resting state connectivity between cortical and subcortical areas - reviewed in (Filippi et al., 2019). In CBD, the evidence is mixed as, thus far, functional MRI studies in this disease have not differentiated between amyloid positive and amyloid negative participants (also reviewed in (Filippi et al., 2019); in the former where Alzheimer's pathology is the most likely finding at post mortem, functional connections are strengthened; however in the latter where a $4 \mathrm{R}$ tauopathy is likely, functional connections may become inefficient as seen in PSP-RS (Cope et al., 2018).

Synaptic pathology is a common feature in many neurodegenerative diseases (Clare et al., 2010; Herms and Dorostkar, 2016; Kweon et al., 2017). In the related tauopathy of Alzheimer's disease, widespread reduction in synapses have been shown using $\left[{ }^{11} \mathrm{C}\right] \mathrm{UCB}-\mathrm{J}$ 
PET in patients (Mecca et al., 2020), as well as changes to dendritic complexity seen both in vivo as reduced ODI (Parker et al., 2018) and in animal models of Alzheimer's disease (Dorostkar et al., 2015). Similar pre- and postsynaptic losses are seen in the substantia nigra of patients with Parkinson's disease (Bellucci et al., 2016; Reeve et al., 2018), and within the hippocampi of patients with Lewy Body Dementia (Revuelta et al., 2008). The tight coupling of the presynaptic and post-synatpic compartments shown in our study, may therefore extend to pathologies other than primary 4R-tauopathies, where synaptic dysfunction is one of the earliest stages of disease, regardless of the culprit protein aggregate in question. If so, the opportunity to utilise both MRI and PET to understand disease pathogenesis would greatly facilitate cohort studies of individual phenotypic differences, or repeat testing in clinical trials monitoring. Furthermore, the in vivo observation of the tight coupling between the pre- and postsynaptic compartments, offer a new angle of interpretation for future studies utilising either of these methods in isolation; for example if cost, scalability and resources are limited for larger cohort studies, MRI measures of dendritic complexity can offer a close surrogate of presynaptic density, although we appreciate it is not a substitute given the significantly larger effect sizes seen with [ $\left.{ }^{11} \mathrm{C}\right] \mathrm{UCB}$ $\mathrm{J}$ (Figure $3 \mathrm{C}$ and $4 \mathrm{C}$ ). This latter observation, which replicates our previous study in a smaller cohort of patients, may indicate a more severe toxic effect at the presynapse compared to dendritic pathology, although longitudinal studies are required to confirm this. However, it is important to note that ODI should not be taken as a direct representation of the post-synaptic density seen in histological studies. Rather, it provides complementary information to the PET data, with support from histological studies that have shown ODI to be a close surrogate (Grussu et al., 2017).

There are several strengths of this study. First, our NODDI resolution of $1.75 \mathrm{~mm}$ was specifically optimised for the investigation of cortical microstructure, and is higher than previous NODDI studies in early onset AD (2.5 mm) (Parker et al., 2018), Parkinson's disease $(5 \mathrm{~mm})$ (Kamagata et al., 2016) and PSP-RS $(2.0 \mathrm{~mm}$ ) (Mitchell et al., 2019). Second, we use amyloid imaging to exclude patients with CBS likely due to Alzheimer's disease. This helps in reducing the potential underlying pathologies at play in the CBS cohort to $4 \mathrm{R}$ tauopathy, although we acknowledge other pathologies are possible but less likely (Alexander et al., 2014) - in this regard it is reassuring that the spatial patterns of reductions in ODI and [ $\left.{ }^{11} \mathrm{C}\right]$ UCB-J binding are not substantially different between the PSPRS and CBD cohorts. Thirdly, the use of non-parametric permutation analyses also confer additional robustness to our statistical results, since this approach is not reliant on data distributions (Winkler et al., 2014). 
We acknowledge the limitations of our study including the relatively small sample size in our CBD cohort. However, given the large effect sizes seen of ODI and $\left[{ }^{11} \mathrm{C}\right]$ UCB-J binding reduction in both our patient groups, our study was sufficiently powered to examine the relationships between both imaging markers. Secondly, we acknowledge that the MRI measure of ODI is not a measure of post-synaptic density but rather dendritic complexity; PET radioligands targeting the post-synaptic density may therefore provide further useful insights into post-synaptic pathology. Furthermore, although we illustrate a tight correlation between our two measures of synaptic health, we do not show causality in this crosssectional study design, but are working towards this aim through our longitudinal studies. Lastly, we highlight the limitations of clinicopathological correlations, but take reassurance from previous validation studies illustrating a high consistency in the clinicopathological correlations in PSP-RS and in amyloid negative CBS.

Understanding the pathological processes that precede atrophy in neurodegeneration is key not only in expanding our knowledge of the pathophysiology of disease but also in informing the design of clinical trials both in terms of the imaging options for measuring diseaserelated changes and the optimal timing of intervention in the disease process. Our data implicate correlated changes in dendritic microstructure and synaptic density in patients with primary degenerative tauopathies including PSP-RS and CBD. Further cross-validation of ODI with [ $\left.{ }^{11} \mathrm{C}\right] \mathrm{UCB}-\mathrm{J} \mathrm{BP}_{\mathrm{ND}}$ may help further our understanding of the pathophysiology of neurodegeneration, applicable to future studies of early neurodegeneration with a safe and widely available MRI platform.

\section{ACKNOWLEDGMENTS}

The authors thank the research participants and caregivers, the staff at the Wolfson Brain Imaging Centre, and at the Cambridge Centre for Parkinson-Plus. We thank UCB Pharma for providing the precursor for UCB-J synthesis. Infrastructure support was provided by the High Performance Hubs for Clinical Informatics ( $\mathrm{HPHI}$ ), funded by the MRC Research Infrastructure Award (MR/M009041/1).

\section{FUNDING}

The study was funded by the Cambridge University Centre for Parkinson-Plus (RG95450); the National Institute for Health Research Cambridge Biomedical Research Centre (146281); the Wellcome Trust (103838) and the Association of British Neurologists, Patrick Berthoud Charitable Trust (NH: RG99368). EM is supported by Alzheimer's Society Junior Research Fellowship (443 AS JF 18017). RRG is supported by the Guarantors of Brain 
medRxiv preprint doi: https://doi.org/10.1101/2020.12.24.20248838; this version posted December 27, 2020. The copyright holder for this preprint (which was not certified by peer review) is the author/funder, who has granted medRxiv a license to display the preprint in perpetuity.

It is made available under a CC-BY 4.0 International license .

Fellowship (RNAG/474). AL is supported by the Lee Kuan Yew Fitzwilliam Scholarship and the Tan Kah Kee Scholarship. TR has received honoraria from Biogen and the National Institute for Health and Clinical Excellence (NICE).

\section{DECLARATION OF INTERESTS}

James B Rowe serves as an associate editor to Brain and is a non-remunerated trustee of the Guarantors of Brain, Darwin College and the PSP-RS Association (UK). He provides consultancy to Asceneuron, Biogen, UCB, Althira, Astex, SVHealth and has research grants from AZ-Medimmune, Janssen, Lilly as industry partners in the Dementias Platform UK. John T. O'Brien has no conflicts related to this study; unrelated to this work he has received honoraria for work as DSMB chair or member for TauRx, Axon, Eisai, has acted as a consultant for Roche, has received research support from Alliance Medical and Merck. 


\section{REFERENCES}

Alexander, S.K., Rittman, T., Xuereb, J.H., Bak, T.H., Hodges, J.R., Rowe, J.B., 2014. Validation of the new consensus criteria for the diagnosis of corticobasal degeneration. J. Neurol. Neurosurg. Psychiatry 85, 923-927. https://doi.org/10.1136/jnnp-2013307035

Andersson, J.L.R., Graham, M.S., Zsoldos, E., Sotiropoulos, S.N., 2016. Incorporating outlier detection and replacement into a non-parametric framework for movement and distortion correction of diffusion MR images. Neuroimage 141, 556-572.

https://doi.org/10.1016/j.neuroimage.2016.06.058

Armstrong, M.J., Litvan, I., Lang, A.E., Bak, T.H., Bhatia, K.P., Borroni, B., Boxer, A.L., Dickson, D.W., Grossman, M., Hallett, M., Josephs, K.A., Kertesz, A., Lee, S.E., Miller, B.L., Reich, S.G., Riley, D.E., Tolosa, E., Tröster, A.I., Vidailhet, M., Weiner, W.J., 2013. Criteria for the diagnosis of corticobasal degeneration. Neurology 80, 496-503. https://doi.org/10.1212/WNL.0b013e31827f0fd1

Bellucci, A., Mercuri, N.B., Venneri, A., Faustini, G., Longhena, F., Pizzi, M., Missale, C., Spano, P., 2016. Review: Parkinson's disease: from synaptic loss to connectome dysfunction. Neuropathol. Appl. Neurobiol. 42, 77-94.

https://doi.org/10.1111/nan.12297

Bigio, E.H., Vono, M.B., Satumtira, S., Adamson, J., Sontag, E., Hynan, L.S., White, C.L., Baker, M., Hutton, M., 2001. Cortical synapse loss in progressive supranuclear palsy. J. Neuropathol. Exp. Neurol. 60, 403-410. https://doi.org/10.1093/jnen/60.5.403

Blin, J., Vidailhet, M.-J., Pillon, B., Dubois, B., Feve, J.-R., Agid, Y., 1992. Corticobasal degeneration: Decreased and asymmetrical glucose consumption as studied with PET. Mov. Disord. 7, 348-354. https://doi.org/10.1002/mds.870070409

Burgos, N., Cardoso, M.J., Thielemans, K., Modat, M., Pedemonte, S., Dickson, J., Barnes, A., Ahmed, R., Mahoney, C.J., Schott, J.M., Duncan, J.S., Atkinson, D., Arridge, S.R., Hutton, B.F., Ourselin, S., 2014. Attenuation correction synthesis for hybrid PET-MR scanners: Application to brain studies. IEEE Trans. Med. Imaging 33, 2332-2341. https://doi.org/10.1109/TMI.2014.2340135

Burrell, J.R., Hodges, J.R., Rowe, J.B., 2014. Cognition in corticobasal syndrome and progressive supranuclear palsy: A review. Mov. Disord. 29, 684-693. https://doi.org/10.1002/mds.25872

Chen, M.K., Mecca, A.P., Naganawa, M., Finnema, S.J., Toyonaga, T., Lin, S.F., Najafzadeh, S., Ropchan, J., Lu, Y., McDonald, J.W., Michalak, H.R., Nabulsi, N.B., Arnsten, A.F.T., Huang, Y., Carson, R.E., Van Dyck, C.H., 2018. Assessing Synaptic 
Density in Alzheimer Disease with Synaptic Vesicle Glycoprotein 2A Positron Emission Tomographic Imaging. JAMA Neurol. 75, 1215-1224.

https://doi.org/10.1001/jamaneurol.2018.1836

Clare, R., King, V.G., Wirenfeldt, M., Vinters, H. V., 2010. Synapse loss in dementias. J. Neurosci. Res. https://doi.org/10.1002/jnr.22392

Colgan, N., Siow, B., O'Callaghan, J.M., Harrison, I.F., Wells, J.A., Holmes, H.E., Ismail, O., Richardson, S., Alexander, D.C., Collins, E.C., Fisher, E.M., Johnson, R., Schwarz, A.J., Ahmed, Z., O'Neill, M.J., Murray, T.K., Zhang, H., Lythgoe, M.F., 2016. Application of neurite orientation dispersion and density imaging (NODDI) to a tau pathology model of Alzheimer's disease. Neuroimage 125, 739-744.

https://doi.org/10.1016/j.neuroimage.2015.10.043

Cope, T.E., Rittman, T., Borchert, R.J., Jones, P.S., Vatansever, D., Allinson, K., Passamonti, L., Vazquez Rodriguez, P., Bevan-Jones, W.R., O’Brien, J.T., Rowe, J.B., 2018. Tau burden and the functional connectome in Alzheimer's disease and progressive supranuclear palsy. Brain 141, 550-567.

https://doi.org/10.1093/brain/awx347

Cox, S.R., Ritchie, S.J., Tucker-Drob, E.M., Liewald, D.C., Hagenaars, S.P., Davies, G., Wardlaw, J.M., Gale, C.R., Bastin, M.E., Deary, I.J., 2016. Ageing and brain white matter structure in 3,513 UK Biobank participants. Nat. Commun. 7, 13629. https://doi.org/10.1038/ncomms 13629

Coyle-Gilchrist, I.T.S., Dick, K.M., Patterson, K., Rodríquez, P.V., Wehmann, E., Wilcox, A., Lansdall, C.J., Dawson, K.E., Wiggins, J., Mead, S., Brayne, C., Rowe, J.B., 2016.

Prevalence, characteristics, and survival of frontotemporal lobar degeneration syndromes. Neurology 86, 1736-1743.

https://doi.org/10.1212/WNL.0000000000002638

Dahnke, R., Yotter, R.A., Gaser, C., 2013. Cortical thickness and central surface estimation. Neuroimage 65, 336-348. https://doi.org/10.1016/j.neuroimage.2012.09.050

DeKosky, S.T., Scheff, S.W., 1990. Synapse loss in frontal cortex biopsies in Alzheimer's disease: Correlation with cognitive severity. Ann. Neurol. 27, 457-464.

https://doi.org/10.1002/ana.410270502

Dickson, D.W., Kouri, N., Murray, M.E., Josephs, K.A., 2011. Neuropathology of frontotemporal lobar degeneration-Tau (FTLD-Tau), in: Journal of Molecular Neuroscience. Springer, pp. 384-389. https://doi.org/10.1007/s12031-011-9589-0

Dorostkar, M.M., Zou, C., Blazquez-Llorca, L., Herms, J., 2015. Analyzing dendritic spine pathology in Alzheimer's disease: problems and opportunities. Acta Neuropathol. https://doi.org/10.1007/s00401-015-1449-5

Filippi, M., Sarasso, E., Agosta, F., 2019. Resting-state Functional MRI in Parkinsonian 
Syndromes. Mov. Disord. Clin. Pract. 6, 104-117. https://doi.org/10.1002/mdc3.12730 Finnema, S.J., Nabulsi, N.B., Eid, T., Detyniecki, K., Lin, S.F., Chen, M.K., Dhaher, R., Matuskey, D., Baum, E., Holden, D., Spencer, D.D., Mercier, J., Hannestad, J., Huang, Y., Carson, R.E., 2016. Imaging synaptic density in the living human brain. Sci. Transl. Med. 8. https://doi.org/10.1126/scitranslmed.aaf6667

Finnema, S.J., Nabulsi, N.B., Mercier, J., Lin, S., Chen, M.-K., Matuskey, D., Gallezot, J.-D., Henry, S., Hannestad, J., Huang, Y., Carson, R.E., 2017. Kinetic evaluation and testretest reproducibility of [ ${ }^{11} \mathrm{C}$ ]UCB-J, a novel radioligand for positron emission tomography imaging of synaptic vesicle glycoprotein 2A in humans. J. Cereb. Blood Flow Metab. 0271678X1772494. https://doi.org/10.1177/0271678X17724947

Fukutomi, H., Glasser, M.F., Zhang, H., Autio, J.A., Coalson, T.S., Okada, T., Togashi, K., Van Essen, D.C., Hayashi, T., 2018. Neurite imaging reveals microstructural variations in human cerebral cortical gray matter. Neuroimage 1-12.

https://doi.org/10.1016/j.neuroimage.2018.02.017

Genç, E., Fraenz, C., Schlüter, C., Friedrich, P., Hossiep, R., Voelkle, M.C., Ling, J.M., Güntürkün, O., Jung, R.E., 2018. Diffusion markers of dendritic density and arborization in gray matter predict differences in intelligence. Nat. Commun. 9.

https://doi.org/10.1038/s41467-018-04268-8

Grussu, F., Schneider, T., Tur, C., Yates, R.L., Tachrount, M., lanuş, A., Yiannakas, M.C., Newcombe, J., Zhang, H., Alexander, D.C., DeLuca, G.C., Gandini Wheeler-Kingshott, C.A.M., 2017. Neurite dispersion: a new marker of multiple sclerosis spinal cord pathology? Ann. Clin. Transl. Neurol. 4, 663-679. https://doi.org/10.1002/acn3.445

Harms, R.L., Fritz, F.J., Tobisch, A., Goebel, R., Roebroeck, A., 2017. Robust and fast nonlinear optimization of diffusion MRI microstructure models. Neuroimage 155, 82-96. https://doi.org/10.1016/j.neuroimage.2017.04.064

Harris, K.M., Kater, S.B., 1994. Dendritic Spines: Cellular Specializations Imparting Both Stability and Flexibility to Synaptic Function. Annu. Rev. Neurosci. https://doi.org/10.1146/annurev.ne.17.030194.002013

Herms, J., Dorostkar, M.M., 2016. Dendritic Spine Pathology in Neurodegenerative Diseases. Annu. Rev. Pathol. Mech. Dis 11, 221-50. https://doi.org/10.1146/annurevpathol-012615-044216

Hoffmann, N.A., Dorostkar, M.M., Blumenstock, S., Goedert, M., Herms, J., 2014. Impaired plasticity of cortical dendritic spines in P301S tau transgenic mice. Acta Neuropathol. Commun. 2, 82. https://doi.org/10.1186/2051-5960-1-82

Höglinger, G.U., Respondek, G., Stamelou, M., Kurz, Carolin, Josephs, K.A., Lang, A.E., Mollenhauer, B., Müller, U., Nilsson, C., Whitwell, J.L., Arzberger, T., Englund, E., Gelpi, E., Giese, A., Irwin, D.J., Meissner, W.G., Pantelyat, A., Rajput, A., van Swieten, 
J.C., Troakes, C., Antonini, A., Bhatia, K.P., Bordelon, Y., Compta, Y., Corvol, J.C., Colosimo, C., Dickson, D.W., Dodel, R., Ferguson, L., Grossman, M., Kassubek, J., Krismer, F., Levin, J., Lorenzl, S., Morris, H.R., Nestor, P., Oertel, W.H., Poewe, W., Rabinovici, G., Rowe, J.B., Schellenberg, G.D., Seppi, K., van Eimeren, T., Wenning, G.K., Boxer, A.L., Golbe, L.I., Litvan, I., Boxer, A.L., Rajput, A., Pantelyat, A., Antonini, A., Lang, A.E., Giese, A., Mollenhauer, B., Colosimo, C., Kurz, Caroline, Nilsson, C., Troakes, C., Irwin, D.J., Dickson, D.W., Gelpi, E., Krismer, F., Schellenberg, G.D., Respondek, G., Rabinovici, G., Wenning, G.K., Höglinger, G.U., Morris, H.R., Litvan, I., Rowe, J.B., Kassubek, J., Corvol, J.C., Whitwell, J.L., Levin, J., van Swieten, J., Bhatia, K.P., Josephs, K.A., Seppi, K., Golbe, L.I., Grossman, M., Nestor, P., Dodel, R., Lorenzl, S., van Eimeren, T., Arzberger, T., Müller, U., Meissner, W.G., Poewe, W., Oertel, W.H., Compta, Y., Bordelon, Y., 2017. Clinical diagnosis of progressive supranuclear palsy: The movement disorder society criteria. Mov. Disord. 32, 853-864. https://doi.org/10.1002/mds.26987

Holland, N., Jones, P.S., Savulich, G., Wiggins, J.K., Hong, Y.T., Fryer, T.D., Manavaki, R., Sephton, S.M., Boros, I., Malpetti, M., Hezemans, F.H., Aigbirhio, F.I., Coles, J.P., O'Brien, J., Rowe, J.B., 2020. Synaptic Loss in Primary Tauopathies Revealed by [ $<\mathrm{scp}>{ }^{11} \mathrm{C}</ \mathrm{scp}>$ ] $<\mathrm{scp}>$ UCB-J $</ \mathrm{scp}>$ Positron Emission Tomography. Mov. Disord. mds.28188. https://doi.org/10.1002/mds.28188

Hughes, L.E., Ghosh, B.C.P., Rowe, J.B., 2013. Reorganisation of brain networks in frontotemporal dementia and progressive supranuclear palsy. Neurolmage Clin. 2, 459-468. https://doi.org/10.1016/j.nicl.2013.03.009

Hughes, L.E., Rowe, J.B., Ghosh, B.C.P., Carlyon, R.P., Plack, C.J., Gockel, H.E., 2014.

The binaural masking level difference: Cortical correlates persist despite severe brain stem atrophy in progressive supranuclear palsy. J. Neurophysiol. 112, 3086-3094. https://doi.org/10.1152/jn.00062.2014

Jabbari, E., Holland, N., Chelban, V., Jones, P.S., Lamb, R., Rawlinson, C., Guo, T., Costantini, A.A., Tan, M.M.X., Heslegrave, A.J., Roncaroli, F., Klein, J.C., Ansorge, O., Allinson, K.S.J., Jaunmuktane, Z., Holton, J.L., Revesz, T., Warner, T.T., Lees, A.J., Zetterberg, H., Russell, L.L., Bocchetta, M., Rohrer, J.D., Williams, N.M., Grosset, D.G., Burn, D.J., Pavese, N., Gerhard, A., Kobylecki, C., Leigh, P.N., Church, A., Hu, M.T.M., Woodside, J., Houlden, H., Rowe, J.B., Morris, H.R., 2019. Diagnosis Across the Spectrum of Progressive Supranuclear Palsy and Corticobasal Syndrome. JAMA Neurol. https://doi.org/10.1001/jamaneurol.2019.4347 Jack, C.R., Wiste, H.J., Weigand, S.D., Therneau, T.M., Lowe, V.J., Knopman, D.S., Gunter, J.L., Senjem, M.L., Jones, D.T., Kantarci, K., Machulda, M.M., Mielke, M.M., Roberts, R.O., Vemuri, P., Reyes, D.A., Petersen, R.C., 2017. Defining imaging biomarker cut 
points for brain aging and Alzheimer's disease. Alzheimer's Dement. 13, 205-216. https://doi.org/10.1016/j.jalz.2016.08.005

Juh, R., Kim, J., Moon, D., Choe, B., Suh, T., 2004. Different metabolic patterns analysis of Parkinsonism on the 18 F-FDG PET. Eur. J. Radiol. 51, 223-233.

https://doi.org/10.1016/S0720-048X(03)00214-6

Kamagata, K., Hatano, T., Okuzumi, A., Motoi, Y., Abe, O., Shimoji, K., Kamiya, K., Suzuki, M., Hori, M., Kumamaru, K.K., Hattori, N., Aoki, S., 2016. Neurite orientation dispersion and density imaging in the substantia nigra in idiopathic Parkinson disease. Eur. Radiol. 26, 2567-2577. https://doi.org/10.1007/s00330-015-4066-8

Koole, M., van Aalst, J., Devrome, M., Mertens, N., Serdons, K., Lacroix, B., Mercier, J., Sciberras, D., Maguire, P., Van Laere, K., 2019. Quantifying SV2A density and drug occupancy in the human brain using [ 11 C]UCB-J PET imaging and subcortical white matter as reference tissue. Eur. J. Nucl. Med. Mol. Imaging 46, 396-406. https://doi.org/10.1007/s00259-018-4119-8

Kovacs, G.G., Lukic, M.J., Irwin, D.J., Arzberger, T., Respondek, G., Lee, E.B., Coughlin, D., Giese, A., Grossman, M., Kurz, C., McMillan, C.T., Gelpi, E., Compta, Y., van Swieten, J.C., Laat, L.D., Troakes, C., Al-Sarraj, S., Robinson, J.L., Roeber, S., Xie, S.X., Lee, V.M.-Y., Trojanowski, J.Q., Höglinger, G.U., 2020. Distribution patterns of tau pathology in progressive supranuclear palsy. Acta Neuropathol. 1-21.

https://doi.org/10.1007/s00401-020-02158-2

Kweon, J.H., Kim, S., Lee, S.B., 2017. The cellular basis of dendrite pathology in neurodegenerative diseases. BMB Rep. 50, 5-11.

https://doi.org/10.5483/BMBRep.2017.50.1.131

Leemans, A., Jones, D.K., 2009. The B-matrix must be rotated when correcting for subject motion in DTI data. Magn. Reson. Med. 61, 1336-49.

https://doi.org/10.1002/mrm.21890

Lipton, A.M., Munro Cullum, C., Satumtira, S., Sontag, E., Hynan, L.S., White, C.L., Bigio, E.H., 2001. Contribution of asymmetric synapse loss to lateralizing clinical deficits in frontotemporal dementias. Arch. Neurol. 58, 1233-1239.

https://doi.org/10.1001/archneur.58.8.1233

Litvan, I., Agid, Y., Calne, D., Campbell, G., Dubois, B., Duvoisin, R.C., Goetz, C.G., Golbe, L.I., Grafman, J., Growdon, J.H., Hallett, M., Jankovic, J., Quinn, N.P., Tolosa, E., Zee, D.S., 1996. Clinical research criteria for the diagnosis of progressive supranuclear palsy (Steele-Richardson-Olszewski syndrome): Report of the NINDS-SPSP-RS International Workshop. Neurology. https://doi.org/10.1212/WNL.47.1.1

Manavaki, R., Hong, Y., Fryer, T.D., 2019. Brain MRI coil attenuation map processing for the GE SIGNA PET/MR: Impact on PET image quantification and uniformity. IEEE Nucl. 
Sci. Symp. Med. Imaging Conf. Proceedings.

Mecca, A.P., Chen, M., O’Dell, R.S., Naganawa, M., Toyonaga, T., Godek, T.A., Harris, J.E., Bartlett, H.H., Zhao, W., Nabulsi, N.B., Wyk, B.C. Vander, Varma, P., Arnsten, A.F.T., Huang, Y., Carson, R.E., Dyck, C.H., 2020. In vivo measurement of widespread synaptic loss in Alzheimer's disease with SV2A PET. Alzheimer's Dement. alz.12097. https://doi.org/10.1002/alz.12097

Mitchell, T., Archer, D.B., Chu, W.T., Coombes, S.A., Lai, S., Wilkes, B.J., McFarland, N.R., Okun, M.S., Black, M.L., Herschel, E., Simuni, T., Comella, C., Xie, T., Li, H., Parrish, T.B., Kurani, A.S., Corcos, D.M., Vaillancourt, D.E., 2019. Neurite orientation dispersion and density imaging (NODDI) and free-water imaging in Parkinsonism. Hum. Brain Mapp. 40, 5094-5107. https://doi.org/10.1002/hbm.24760

Mosconi, L., Tsui, W.H., De Santi, S., Li, J., Rusinek, H., Convit, A., Li, Y., Boppana, M., De Leon, M.J., 2005. Reduced hippocampal metabolism in MCI and AD: Automated FDGPET image analysis. Neurology 64, 1860-1867.

https://doi.org/10.1212/01.WNL.0000163856.13524.08

Mowinckel, A.M., Vidal-Piñeiro, D., 2019. Visualisation of Brain Statistics with R-packages ggseg and ggseg3d. arXiv. https://doi.org/10.1177/2515245920928009

Parker, T.D., Slattery, C.F., Zhang, J., Nicholas, J.M., Paterson, R.W., Foulkes, A.J.M., Malone, I.B., Thomas, D.L., Modat, M., Cash, D.M., Crutch, S.J., Alexander, D.C., Ourselin, S., Fox, N.C., Zhang, H., Schott, J.M., 2018. Cortical microstructure in young onset Alzheimer's disease using neurite orientation dispersion and density imaging. Hum. Brain Mapp. 39, 3005-3017. https://doi.org/10.1002/hbm.24056

Prados, F., Cardoso, M.J., Burgos, N., Wheeler-Kingshott, C., Ourselin, S., Angela, C., Gandini, M., Ourselin, S., 2016. NiftyWeb: web based platform for image processing on the cloud, in: 24th Scientific Meeting and Exhibition of the International Society for Magnetic Resonance in Medicine (ISMRM).

Reeve, A.K., Grady, J.P., Cosgrave, E.M., Bennison, E., Chen, C., Hepplewhite, P.D., Morris, C.M., 2018. Mitochondrial dysfunction within the synapses of substantia nigra neurons in Parkinson's disease. npj Park. Dis. 4, 1-10. https://doi.org/10.1038/s41531018-0044-6

Revuelta, G.J., Rosso, A., Lippa, C.F., 2008. Neuritic pathology as a correlate of synaptic loss in dementia with Lewy bodies. Am. J. Alzheimers. Dis. Other Demen. 23, 97-102. https://doi.org/10.1177/1533317507310565

Rocher, A.B., Crimins, J.L., Amatrudo, J.M., Kinson, M.S., Todd-Brown, M.A., Lewis, J., Luebke, J.I., 2010. Structural and functional changes in tau mutant mice neurons are not linked to the presence of NFTs. Exp. Neurol. 223, 385-393.

https://doi.org/10.1016/j.expneurol.2009.07.029 
Rösler, T.W., Tayaranian Marvian, A., Brendel, M., Nykänen, N.P., Höllerhage, M., Schwarz, S.C., Hopfner, F., Koeglsperger, T., Respondek, G., Schweyer, K., Levin, J., Villemagne, V.L., Barthel, H., Sabri, O., Müller, U., Meissner, W.G., Kovacs, G.G., Höglinger, G.U., 2019. Four-repeat tauopathies. Prog. Neurobiol. https://doi.org/10.1016/j.pneurobio.2019.101644

Rossano, S., Toyonaga, T., Finnema, S.J., Naganawa, M., Lu, Y., Nabulsi, N., Ropchan, J., De Bruyn, S., Otoul, C., Stockis, A., Nicolas, J.M., Martin, P., Mercier, J., Huang, Y., Maguire, R.P., Carson, R.E., 2019. Assessment of a white matter reference region for 11C-UCB-J PET quantification. J. Cereb. Blood Flow Metab.

https://doi.org/10.1177/0271678X19879230

Sami, S., Williams, N., Hughes, L.E., Cope, T.E., Rittman, T., Coyle-Gilchrist, I.T.S., Henson, R.N., Rowe, J.B., 2018. Neurophysiological signatures of Alzheimer's disease and frontotemporal lobar degeneration: Pathology versus phenotype. Brain 141, 25002510. https://doi.org/10.1093/brain/awy180

Schikorski, T., Stevens, C.F., 1999. Quantitative fine-structural analysis of olfactory cortical synapses. Proc. Natl. Acad. Sci. U. S. A. 96, 4107-4112.

https://doi.org/10.1073/pnas.96.7.4107

Schilling, K.G., Janve, V., Gao, Y., Stepniewska, I., Landman, B.A., Anderson, A.W., 2018. Histological validation of diffusion MRI fiber orientation distributions and dispersion. Neuroimage. https://doi.org/10.1016/j.neuroimage.2017.10.046

Schofield, E.C., Hodges, J.R., Bak, T.H., Xuereb, J.H., Halliday, G.M., 2012. The relationship between clinical and pathological variables in Richardson's syndrome. J. Neurol. 259, 482-490. https://doi.org/10.1007/s00415-011-6205-8

Seiger, R., Ganger, S., Kranz, G.S., Hahn, A., Lanzenberger, R., 2018. Cortical Thickness Estimations of FreeSurfer and the CAT12 Toolbox in Patients with Alzheimer's Disease and Healthy Controls. J. Neuroimaging 28, 515-523. https://doi.org/10.1111/jon.12521

Slattery, C.F., Zhang, J., Paterson, R.W., Foulkes, A.J.M., Carton, A., Macpherson, K., Mancini, L., Thomas, D.L., Modat, M., Toussaint, N., Cash, D.M., Thornton, J.S., Henley, S.M.D., Crutch, S.J., Alexander, D.C., Ourselin, S., Fox, N.C., Zhang, H., Schott, J.M., 2017. ApoE influences regional white-matter axonal density loss in Alzheimer's disease. Neurobiol. Aging 57, 8-17.

https://doi.org/10.1016/j.neurobiolaging.2017.04.021

Slattery, C.F., Zhang, J., Paterson, R.W., Foulkes, A.J.M., Mancini, L., Thomas, D.L., Modat, M., Toussaint, N., Cash, D.M., Thornton, J.S., Alexander, D.C., Ourselin, S., Fox, N.C., Zhang, H., Schott, J.M., 2015. Neurite orientation dispersion and density imaging (NODDI) in young-onset Alzheimer's disease and its syndromic variants. Alzheimer's Dement. 11, P91. https://doi.org/10.1016/j.jalz.2015.06.156 
Terry, R.D., Masliah, E., Salmon, D.P., Butters, N., DeTeresa, R., Hill, R., Hansen, L.A., Katzman, R., 1991. Physical basis of cognitive alterations in alzheimer's disease:

Synapse loss is the major correlate of cognitive impairment. Ann. Neurol. 30, 572-580. https://doi.org/10.1002/ana.410300410

Usenovic, M., Niroomand, S., Drolet, R.E., Yao, L., Gaspar, R.C., Hatcher, N.G., Schachter, J., Renger, J.J., Parmentier-Batteur, S., 2015. Internalized tau oligomers cause neurodegeneration by inducing accumulation of pathogenic tau in human neurons derived from induced pluripotent stem cells. J. Neurosci. 35, 14234-14250.

https://doi.org/10.1523/JNEUROSCI.1523-15.2015

Wang, Y., Mandelkow, E., 2016. Tau in physiology and pathology. Nat. Rev. Neurosci. https://doi.org/10.1038/nrn.2015.1

Winkler, A.M., Ridgway, G.R., Webster, M.A., Smith, S.M., Nichols, T.E., 2014. Permutation inference for the general linear model. Neuroimage 92, 381-397. https://doi.org/10.1016/j.neuroimage.2014.01.060

Wu, Y., Carson, R.E., 2002. Noise reduction in the simplified reference tissue model for neuroreceptor functional imaging. J. Cereb. Blood Flow Metab.

https://doi.org/10.1097/01.WCB.0000033967.83623.34

Yoshiyama, Y., Higuchi, M., Zhang, B., Huang, S.M., Iwata, N., Saido, T.C., Maeda, J., Suhara, T., Trojanowski, J.Q., Lee, V.M.Y., 2007. Synapse Loss and Microglial Activation Precede Tangles in a P301S Tauopathy Mouse Model. Neuron 53, 337-351. https://doi.org/10.1016/j.neuron.2007.01.010

Yotter, R.A., Dahnke, R., Thompson, P.M., Gaser, C., 2011a. Topological correction of brain surface meshes using spherical harmonics. Hum. Brain Mapp. 32, 1109-1124.

https://doi.org/10.1002/hbm.21095

Yotter, R.A., Thompson, P.M., Gaser, C., 2011b. Algorithms to Improve the Reparameterization of Spherical Mappings of Brain Surface Meshes. J. Neuroimaging 21, 1-14. https://doi.org/10.1111/j.1552-6569.2010.00484.x

Zhang, H., Schneider, T., Wheeler-Kingshott, C.A., Alexander, D.C., 2012. NODDI: Practical in vivo neurite orientation dispersion and density imaging of the human brain.

Neuroimage 61, 1000-1016. https://doi.org/10.1016/j.neuroimage.2012.03.072 